\title{
Female risk-adjusted survival advantage after injuries caused by falls, traffic or assault: a nationwide 11-year study
}

Robert Larsen ${ }^{1,2,4^{*}}$ (D), Denise Bäckström ${ }^{1,3}$, Mats Fredrikson ${ }^{1}$, Ingrid Steinvall ${ }^{4}$, Rolf Gedeborg ${ }^{5}$ and Folke Sjoberg ${ }^{1,2,4}$

\begin{abstract}
Background: A female survival advantage after injury has been observed, and animal models of trauma have suggested either hormonal or genetic mechanisms as component causes. Our aim was to compare age and riskadjusted sex-related mortality in hospital for the three most common mechanisms of injury in relation to hormonal effects as seen by age.

Methods: All hospital admissions for injury in Sweden during the period 2001-2011 were retrieved from the National Patient Registry and linked to the Cause of Death Registry. The International Classification of Diseases Injury Severity Score (ICISS) was used to adjust for injury severity, and the Charlson Comorbidity Index to adjust for comorbidity. Age categories ( $0-14,15-50$, and $\geq 51$ years) were used to represent pre-menarche, reproductive and post- menopausal women.

Results: Women had overall a survival benefit (OR $0.51 ; 95 \% \mathrm{Cl} 0.50$ to 0.53$)$ after adjustment for injury severity and comorbidity. A similar pattern was seen across the age categories (0-14 years OR 0.56 ( $95 \%$ Cl 0.25 to 1.25), 15-50 years OR 0.70 ( $95 \% \mathrm{Cl} 0.57$ to 0.87 ), and $\geq 51$ years OR 0.49 ( $95 \% \mathrm{Cl} 0.48$ to 0.51$)$ ).

Conclusion: In this 11-year population-based study we found no support for an oestrogen-related mechanism to explain the survival advantage for females compared to males following hospitalisation for injury.
\end{abstract}

Keywords: Risk-adjusted mortality, ICISS, Trauma, Injury, Nationwide, Epidemiological

\section{Introduction}

A female survival advantage is well known [1-5], and is not restricted to particular regions or ethnicities. The magnitude of this difference is substantial, e.g. Japanese women outlive Japanese men by six years [6]. But it is interesting that it has not been convincingly reflected in the outcomes of medical diseases, though the same female survival advantage has been shown in models of trauma and sepsis in animals $[7,8]$. Knowledge of the underlying mechanism of a female survival benefit are important as it may provide clues as to improve trauma care outcomes.

\footnotetext{
* Correspondence: robert.larsen@liu.se

${ }^{1}$ Department of Clinical and Experimental Medicine, Linkoping University, Linkoping, Sweden

2Department of Anaesthesiology and Intensive Care, and Department of Medical and Health Sciences, Linkoping University, S-58185 Linkoping, Sweden

Full list of author information is available at the end of the article
}

In clinical studies of the outcome of injury the results regarding the potential impact of sex have been contradictory, in that some have shown a female advantage, some a disadvantage, and some no difference [9-17]. A national study on Swedish intensive care unit patients [18] showed similar survival rates for men and women, but male patients had significantly more interventions. Recent studies in trauma have suggested a female survival advantage [19], also after adjustment for age and coexisting diseases [20].

Two physiological mechanisms were suggested in models of trauma in animals to explain such female survival advantage: hormonal response [19] to injury, or genetic advantage in the physiological response to injury [21]. Differences in health care could also potentially contribute to a difference in outcome. A study by Gomez found that a lower proportion of female patients, compared to males, were transferred to trauma centres [22].

(c) The Author(s). 2019 Open Access This article is distributed under the terms of the Creative Commons Attribution 4.0 International License (http://creativecommons.org/licenses/by/4.0/), which permits unrestricted use, distribution, and reproduction in any medium, provided you give appropriate credit to the original author(s) and the source, provide a link to the Creative Commons license, and indicate if changes were made. The Creative Commons Public Domain Dedication waiver (http://creativecommons.org/publicdomain/zero/1.0/) applies to the data made available in this article, unless otherwise stated. 
Using age as a surrogate marker for female sex hormonal levels, it might be possible to differentiate between hormonal effects in a retrospective registry study. In addition, we can adjust for comorbidity, and stratify the mechanisms of trauma into three major well-defined subgroups of injuries, in order to improve comparison and identify independent associations between sex and survival following trauma.

Our main hypothesis was that oestrogen is protective and the main contributing factor for female survival advantage in trauma. The hypothesis is further supported by a clinical trial in which the effect on female trauma patients is examined as a sub analysis [17].

\section{Methods}

\section{Patients studied}

All hospital admissions for falls, road traffic crashes, or assault during the years 2001-2011 in Sweden were retrieved from the National Patient Registry (which covers all admissions to Swedish hospitals since 1987), and the Cause of Death Registry (which covers all deaths of Swedish citizens). Patients who died before reaching hospital or who had injuries that did not require hospital admission were not included. For patients who were transferred between departments during treatment for the same injury we used the date of admission and diagnoses from the first record and the date of discharge from the last admission. These records were linked to all records in the Cause of Death Registry that had "injury" as the main cause of death (V01-Y98.9) using the unique personal identification number given to everyone who lives permanently in Sweden. Records from which information on age, sex, date of admission, or mechanism of injury was missing were excluded from the analyses [20].

Those in which the cause of injury was "fall" (W00-W19), "traffic incident" (V01-V99), or "assault" (X85-Y09) were then selected for further study (Fig. 1). A few observations $(n=292,0.036 \%)$ were classified in more than one group, and they were excluded.

\section{Identification of death and 30-day mortality}

Data from the Causes of Death Registry were available until 31 December 2012, which allowed at least 12 months' follow-up after the date of admission to hospital (considered to be the index date of the injury). Thirty-day mortality was calculated to include most of the patients who died as a direct result of the injury, and to exclude those who died mainly of other causes.

\section{Severity of injury}

The Injury Severity Score (ISS) has long been regarded as the standard measure of severity of injury. In 1996 Osler et al. developed a score based on International Classification of Disease (ICD)-9 hospital discharge diagnoses (ICISS) [23], so that they could use large administrative databases with diagnostic codes. Later studies showed that

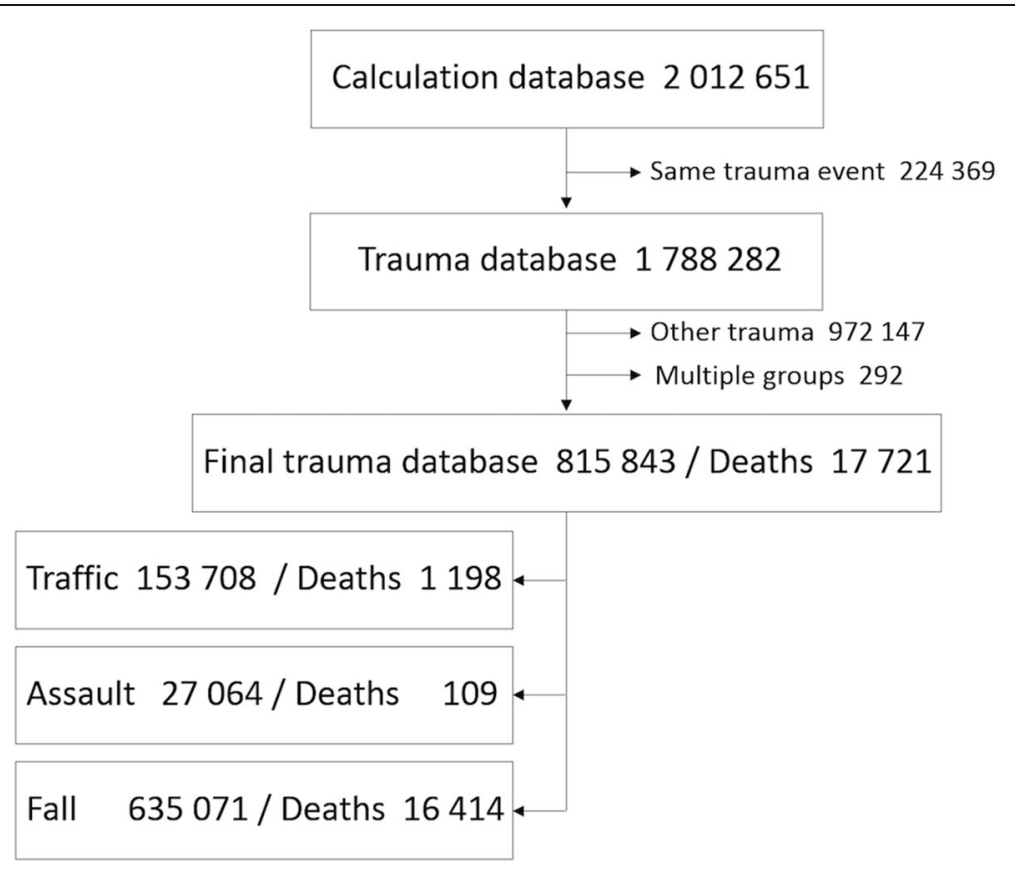

Fig. 1 Flowchart showing selection of patients. Calculation database: data from National Patient Registry and Cause of Death Registry combined. Trauma database: removal of duplicates (224369) in same trauma event. Final trauma database: removal of other mechanisms than fall, traffic and assault, and of the 292 trauma recordings for patients who were classified as having more than one mechanism. The Final trauma database was used for all calculations 
ICISS calculated from ICD10 was superior and allowed a more accurate estimate of the severity of injury [24].

Duplicate ICD10 codes in the National Patient Registry were omitted before calculating the ICISS score. The diagnosis-specific probabilities were estimated using the main injury diagnosis codes and up to nine secondary codes.

We used ICISS as the risk-adjustment for 30-day mortality counting from the first hospital admission.

\section{Comorbidity}

The Charlson Comorbidity Index (CCI) was calculated using the weighted scale as described in the original paper [25] and the ICD-codes from Christensen et al. [26].

\section{Definition of the hormonal subgroup}

The age group from 15 to 50 years was used to identify postmenarchal and premenopausal women [27]. Sensitivity analyses were performed comparing the age groups $0-10,20-40$, and 60 -, in order to evaluate the potential impact of misclassification due to individual variation in the age for menarche and menopause with same result but lower precision due to lower numbers (data not shown).

\section{Statistical analyses}

Logistic regression models with ICISS, CCI, age (years) and sex, were used to estimate the association between sex and 30-day mortality. Numerical variables were used as linear effects without transformation in the models. The discrimination, i.e. the model's ability to separate those who died from those who survived, was measured by the area under the receiver operating characteristic curve (AUC). Probabilities of less than 0.05 were accepted as significant.

Table 1 Description of the study population characteristics

\begin{tabular}{|c|c|c|c|c|}
\hline & & All & Male & Female \\
\hline No of patients, count (\%) & & $815,843(100)$ & $373,811(46)$ & $442,032(54)$ \\
\hline Deaths, count (\%) & & $17,721(100)$ & $8679(49)$ & $9042(51)$ \\
\hline Age in years, mean (SD) & & $58(29)$ & $49(28)$ & $65(27)$ \\
\hline \multicolumn{5}{|l|}{ Age group } \\
\hline 0-14 years "Premenarche", count (\%) & Total & $95,135(100)$ & $57,506(60)$ & $37,629(40)$ \\
\hline \multirow[t]{2}{*}{ Count, (\% of the number above) } & Deaths & $33(0.03)$ & $23(0.04)$ & $10(0.03)$ \\
\hline & Median ICISS & 0.98 & 0.98 & 0.98 \\
\hline $15-50$ years "Reproductive", count (\%) & Total & $195,582(100)$ & $127,251(65)$ & $68,331(35)$ \\
\hline \multirow[t]{2}{*}{ Count, (\% of the number above) } & Deaths & $591(0.30)$ & $459(0.36)$ & $132(0.19)$ \\
\hline & Median ICISS & 0.97 & 0.97 & 0.98 \\
\hline Over 50 years "Postmenopausal", count (\%) & Total & $525,129(100)$ & $189,054(36)$ & $336,075(64)$ \\
\hline \multirow[t]{2}{*}{ Count, (\% of the number above) } & Deaths & $17,097(3.26)$ & $8197(4.34)$ & $8900(2.65)$ \\
\hline & Median ICISS & 0.93 & 0.94 & 0.93 \\
\hline
\end{tabular}

We used the statistics software Stata (Stata Corp LP 2011-15, Stata version 12-15, College Station, TX, USA) for data management and statistical analyses.

\section{Results}

The study population consisted of 815,843 hospital admissions for the three causes of injury (Fig. 1). Fifty-four percent were female. The mean age was 58 (range 0-111) years, and women were significantly older than men. Crude 30 -day mortality was $2.2 \%$, with a lower crude mortality for women $(p<0.001)$ with a difference of $0.3 \%$ between the groups (men $2.3 \%$ and women $2.0 \%$ ). Median ICISS decreased with age group but no statistical difference between the sexes were able to be detected. Thirty-day mortality increased with age group, and male sex was over-represented in crude mortality throughout the groups (Table 1).

The main result was that women overall in the entire study population had a survival benefit (OR $0.51,95 \% \mathrm{CI}$ 0.50 to 0.53 ) after adjustment for injury severity and comorbidity. Subgroup analysis showed that the pattern was similar across the three age groups. When doing separate analyses for the severely injured $($ ICISS $<=0.85$ ) the same pattern were obvious (OR $0.74,95 \%$ CI 0.69 to 0.79 ). In premenarche (OR $0.56 ; 95 \%$ CI 0.25 to 1.25 ), during reproductive age (OR $0.70 ; 95 \%$ CI 0.57 to 0.87 ), and postmenopausal (OR 0.49; 95\% CI 0.48 to 0.51), although precision in the premenarche risk estimate was low due to the relatively few deaths (Table 2). When we assessed smaller groups based on age to avoid misclassiwere evident, but there was more uncertainty in the estimated associations (Fig. 2). The mortality increased exponentially with age (Table 3 ). fication of the hormonal concentration, the same trends 
Table 2 Logistic regression for 30-day mortality including subgroup analysis

\begin{tabular}{|c|c|c|c|c|c|}
\hline & OR & $\mathrm{p}$ & $95 \% \mathrm{Cl}$ & $R^{2 a}$ & AUC \\
\hline Total & & $<0.001$ & & 0.215 & 0.876 \\
\hline ICISS & $<0.001$ & $<0.001$ & $<0.001$ to $<0.001$ & & \\
\hline $\mathrm{CCl}$ & 1.269 & $<0.001$ & 1.253 to 1.283 & & \\
\hline Female & 0.512 & $<0.001$ & 0.496 to 0.529 & & \\
\hline Age (years) & 1.075 & $<0.001$ & 1.074 to 1.077 & & \\
\hline Constant & 10.422 & $<0.001$ & 8.706 to 12.475 & & \\
\hline Pre menarche & & $<0.001$ & & 0.255 & 0.894 \\
\hline ICISS & $<0.001$ & $<0.001$ & $<0.001$ to $<0.001$ & & \\
\hline $\mathrm{CCl}$ & 1.125 & 0.9270 & 0.092 to 13.832 & & \\
\hline Female & 0.563 & 0.1580 & 0.254 to 1.249 & & \\
\hline Age (years) & 0.956 & 0.2390 & 0.887 to 1.030 & & \\
\hline Constant & 4392.84 & $<0.001$ & 510.493 to $37,800.8$ & & \\
\hline Reproductive & & $<0.001$ & & 0.294 & 0.931 \\
\hline ICISS & $<0.001$ & $<0.001$ & $<0.001$ to $<0.001$ & & \\
\hline $\mathrm{CCl}$ & 1.452 & $<0.001$ & 1.238 to 1.703 & & \\
\hline Female & 0.704 & 0.0010 & 0.573 to 0.865 & & \\
\hline Age (years) & 1.009 & 0.0300 & 1.001 to 1.017 & & \\
\hline Constant & 150.692 & $<0.001$ & 93.326 to 243.320 & & \\
\hline Menopause & & $<0.001$ & & 0.156 & 0.820 \\
\hline ICISS & $<0.001$ & $<0.001$ & $<0.001$ to $<0.001$ & & \\
\hline $\mathrm{CCl}$ & 1.277 & $<0.001$ & 1.262 to 1.292 & & \\
\hline Female & 0.495 & $<0.001$ & 0.479 to 0.511 & & \\
\hline Age (years) & 1.090 & $<0.001$ & 1.088 to 1.092 & & \\
\hline Constant & 2.861 & $<0.001$ & 2.293 to 3.570 & & \\
\hline
\end{tabular}

${ }^{\text {apseudo }} \mathrm{R}^{2}$

Abbreviations: AUC Area under the curve, $\mathrm{CCl}$ Charlson comorbidity index $\mathrm{CI}$ Confidence interval, ICISS International classification of disease injury severity score, $O R$ Odds ratio, $p$ Probability, $R 2$ Coefficient of determination
In analyses within the age subgroups, female sex was still associated with a survival advantage, although these estimates had low precision in the younger age groups due to relatively few deaths (Table 3 ). A separate analysis based on mechanism was included in Additional file 1. It is notable that there was no female survival benefit in the premenarche assault group.

C-statistic analysis showed high values for the AUC in all groups, with the highest value in the reproductive group (Table 2).

\section{Discussion}

The aim of this study was to estimate the association between sex and short-term survival following injury, within age categories reflecting levels of female sexual hormones, and adjusted for injury severity and comorbidity. The study results suggest that the female survival advantage in the predominant causes of injury in Sweden (road traffic, fall, and assault) is not more pronounced in the age range where the levels of female sex hormones are expected to be naturally higher. This suggests that hormonal levels do not mainly explain the female survival advantage following injury.

The survival advantage for females appears consistent across the age categories. If the hormonal component is of major importance, an added survival advantage during the hormone-producing years of life would have been expected. If anything, we observed a somewhat attenuated survival advantage for females during that age span. This further supports that other mechanisms than levels of female sexual hormones explain this difference.

Sensitivity analyses using more restrictive age groups, to reduce potential misclassification of menarche and menopause, provided similar estimates but with lower precision. These results further support the conclusions.

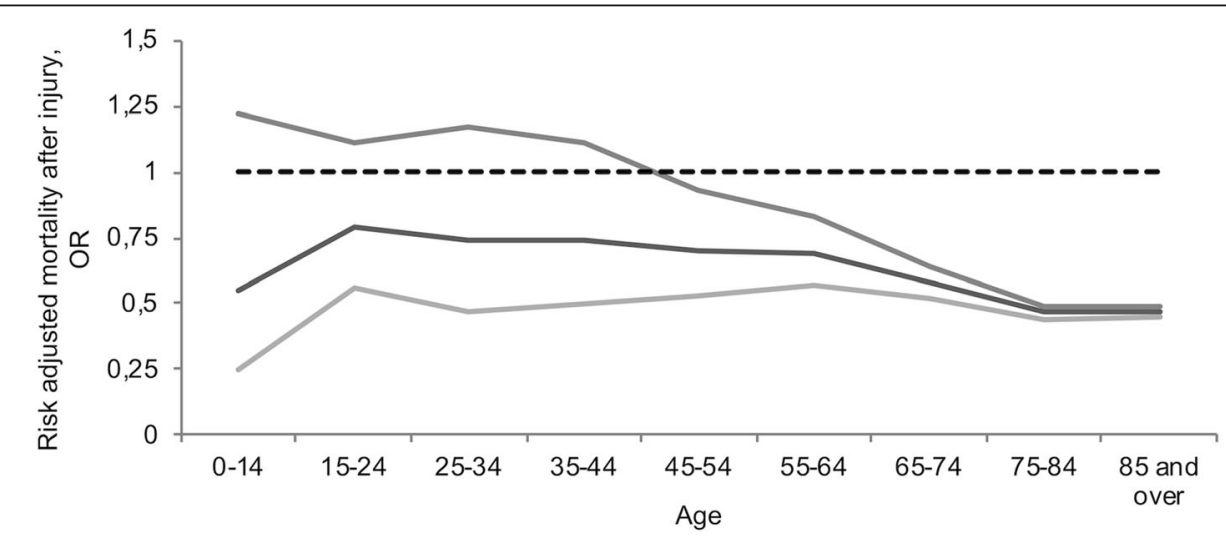

Fig. 2 Graph showing female survival benefit with $95 \% \mathrm{Cl}$ compared to male by age group. Solid black line Female Risk-Adjusted Survival Advantage. Solid grey lines 95\% Cl of Female Risk-Adjusted Survival Advantage. Dotted black line for comparison and male reference 
Table 3 Logistic regression for 30-day mortality by age group and sex

\begin{tabular}{clllll}
\hline \multicolumn{7}{c}{ Coefficient } & $p$ & OR & $95 \% \mathrm{Cl}$ \\
\hline ICISS & & -10.6684 & $<0.001$ & & \\
Age group & Sex & & & & \\
0-14 & Women & -0.1074 & 0.551 & 0.898 & 0.631 to 1.279 \\
$15-25$ & Men & 0.8001 & $<0.001$ & 2.226 & 1.743 to 2.843 \\
$15-25$ & Women & 0.6840 & $<0.001$ & 1.982 & 1.515 to 2.593 \\
$26-35$ & Men & 1.0752 & $<0.001$ & 2.931 & 2.284 to 3.760 \\
$26-35$ & Women & 0.9637 & $<0.001$ & 2.621 & 1.980 to 3.470 \\
$36-45$ & Men & 1.2114 & $<0.001$ & 3.358 & 2.633 to 4.283 \\
$36-45$ & Women & 1.1070 & $<0.001$ & 3.025 & 2.321 to 3.943 \\
$46-55$ & Men & 1.7065 & $<0.001$ & 5.510 & 4.367 to 6.951 \\
$46-55$ & Women & 1.4370 & $<0.001$ & 4.208 & 3.285 to 5.391 \\
$56-65$ & Men & 2.1299 & $<0.001$ & 8.414 & 6.710 to 10.550 \\
$56-65$ & Women & 1.8096 & $<0.001$ & 6.108 & 4.836 to 7.715 \\
$66-75$ & Men & 2.8235 & $<0.001$ & 16.837 & 13.476 to 21.035 \\
$66-75$ & Women & 2.3141 & $<0.001$ & 10.116 & 8.078 to 12.668 \\
$\geq 76$ & Men & 3.9751 & $<0.001$ & 53.255 & 42.774 to 66.303 \\
$\geq 76$ & Women & 3.3639 & $<0.001$ & 28.902 & 23.217 to 35.978 \\
\hline
\end{tabular}

Men age younger than 15 as reference.

Abbreviations: CI Confidence interval, ICISS International classification of

disease injury severity score, $O R$ Odds ratio, $p$ probability

\section{Strengths of the study}

The population-based design with reliable follow-up based on the exact link of personal records with the Cause of Death Registry, even after hospital discharge, and accurate estimates of the severity of injury are notable strengths. The ICISS provides an accurate estimation of the severity of injury [24]. The quality of the coding of injuries in the Swedish National Patient Registry has previously been validated, and is accurate to the fourth position of the code [28]. It has been shown in a comparison among eight countries that the similarities in ICISS are substantial, which further strengthens our results [29]. Previous studies in Sweden have not shown a resource allocation that predisposed to female survival, but have shown that more resources were allocated to men, which argues against such factors being of major importance for differences in survival between men and women [18].

\section{Limitations of the study}

The relatively low number of deaths in the younger groups limits the precision of estimated associations. Another limitation is that we did not include prehospital data in our study, but as previous studies showed no difference in risk-adjusted survival between prehospital and in-hospital mortality [30], adding prehospital data could have increased the precision, but the main results would likely not be different. Another limitation is that the data is not adjusted for interventions (not surgical nor medical) and this is a limitation of the current study. Interventions should be a part of the adjustment in further studies. Another limitation is the expected misclassification of hormonal levels, e.g. from postmenopausal hormonal replacement therapy. This could be further examined in the Swedish setting today by using the Medical Prescription Registry. The notable lack of female survival benefit in the premenarche assault group could be explained by the low number of deceased $(2$ patients) and both of them were male.

\section{Strengths, weaknesses, and important differences in results compared with other studies}

It has previously been shown that Sweden compares well with other countries in the recording and treatment of trauma [29]. Even though coding-errors in ICD-10 are common, the consequences for estimates of the severity of injury are claimed to be minor in most cases [28]. To our knowledge this is the first population-based nationwide study that has investigated ICISS risk-adjusted 30-day survival by sex in patients admitted to hospital. Another strength is that healthcare in Sweden is publicly financed and not dependent on the patient's funds or insurance, which further supports the view that our model is estimating the physiological effect rather than financial or administrative effects of healthcare.

\section{Meaning of the study: Possible explanations and implications for clinicians and policymakers}

This study has shown a risk-adjusted, 30-day, survival advantage after trauma for women compared with men but without major differences across age categories representing expected levels of female sexual hormones. These results do not support the idea that trauma patients should be given oestrogen [31].

\section{Unanswered questions and future research}

In our analyses, sex was a significant risk factor for mortality even after adjustment for injury mechanism and severity. While specific health-care interventions should be evaluated [22], it is also important to try to understand the mechanism behind the observed association between sex and mortality after injury. The higher mortality for men may suggest that men received suboptimal treatment, but previous studies, if anything, support a male advantage in this respect [18].

\section{Conclusion}

In this population-based study over an 11-year period we did not after adjustments for injury severity, age, and co-morbidity find any support for a hormonal effect (oestrogen) explaining a female survival benefit. 


\section{Additional file}

Additional file 1: Supplemental digital content. (DOCX 34 kb)

\author{
Abbreviations \\ AUC: Area under the curve; CCl: Charlson comorbidity index; Cl: Confidence \\ interval; ICD-9/10: International classification of disease version 9/10; \\ ICISS: International classification of disease injury severity score; ISS: Injury \\ severity score; OR: Odds ratio; $\mathrm{R}^{2}$ : Coefficient of determination; SD: Standard \\ deviation
}

\section{Acknowledgements}

Not applicable.

\section{Funding}

This work was supported by, and done at, the Burn Centre, Department of Plastic Surgery, Hand Surgery, and Burns, and the Linkoping University, Linkoping, Sweden. The funders had no role in study design, data collection and analysis, decision to publish, or preparation of the manuscript.

\section{Availability of data and materials}

The data that support the findings of this study are available on request from the corresponding author [RL]. The data are not publicly available due to them containing information that could compromise "research participant privacy".

\section{Authors' contributions}

Study design: RL, FS. Data collection: RL. Data analysis: RL, MF. Data interpretation: RL, DB, MF, IS, RG, FS. Writing: RL, DB, IS, RG, FS. Critical revision: $R L, D B, M F, I S, R G$, FS. The manuscript has been seen and approved by all authors.

\section{Ethics approval and consent to participate}

The study was approved by the Regional Ethics Review Board in Linkoping, Sweden.

\section{Consent for publication}

Not applicable.

\section{Competing interests}

No conflicts of interest where declared by the authors. However, Rolf Gedeborg is also employed by the Medical Products Agency, an agency of the Swedish government. The views expressed in this paper may not reflect the views of the Medical Products Agency.

\section{Publisher's Note}

Springer Nature remains neutral with regard to jurisdictional claims in published maps and institutional affiliations.

\section{Author details}

${ }^{1}$ Department of Clinical and Experimental Medicine, Linkoping University, Linkoping, Sweden. 'Department of Anaesthesiology and Intensive Care, and Department of Medical and Health Sciences, Linkoping University, S-58185 Linkoping, Sweden. ${ }^{3}$ Life Regiment Hussars, K3 Karlsborg, Sweden. ${ }^{4}$ Department of Hand Surgery, Plastic Surgery and Burns, and Department of Clinical and Experimental Medicine, Linkoping University, Linkoping, Sweden. ${ }^{5}$ Department of Surgical Sciences, Anaesthesiology and Intensive Care, Uppsala University, Uppsala, Sweden.

Received: 21 September 2018 Accepted: 6 February 2019 Published online: 15 March 2019

\section{References}

1. Knöferl MW, Jarrar D, Angele MK, Ayala A, Schwacha MG, Bland Kl, et al. $17 \beta$-estradiol normalizes immune responses in ovariectomized females after trauma-hemorrhage. Am J Physiol Cell Physiol. 2001;281(4):1131-8.

2. Angele MK, Frantz MC, Chaudry $\mathrm{IH}$. Gender and sex hormones influence the response to trauma and sepsis: potential therapeutic approaches. Clinics (Sao Paulo). 2006;61(5):479-88.
3. Angele MK, Ayala A, Cioffi WG, Bland Kl, Chaudry IH. Testosterone: the culprit for producing splenocyte immune depression after trauma hemorrhage. Am J Physiol Cell Physiol. 1998;274(6):1530-6.

4. Remmers DE, Cioffi WG, Bland KI, Wang P, Angele MK, Chaudry IH. Testosterone: the crucial hormone responsible for depressing myocardial function in males after trauma-hemorrhage. Ann Surg. 1998;227(6):790-9.

5. Sheth SU, Palange D, Xu DZ, Wei D, Feketeova E, Lu Q, et al. Testosterone depletion or blockade in male rats protects against trauma hemorrhagic shockinduced distant organ injury by limiting gut injury and subsequent production of biologically active mesenteric lymph. J Trauma. 2011;71(6):1652-8.

6. Tokudome S, Hashimoto S, Igata A. Life expectancy and healthy life expectancy of Japan: the fastest graying society in the world. BMC Res Notes. 2016;9(1):482.

7. Choudhry MA, Bland Kl, Chaudry $\mathrm{H}$. Trauma and immune response-effect of gender differences. Injury. 2007;38(12):1382-91.

8. Knöferl MW, Angele MK, Diodato MD, Schwacha MG, Ayala A, Cioffi WG, et al. Female sex hormones regulate macrophage function after traumahemorrhage and prevent increased death rate from subsequent sepsis. Ann Surg. 2002;235(1):105-12.

9. George RL, McGwin G Jr, Metzger J, Chaudry IH, Rue LW III. The association between gender and mortality among trauma patients as modified by age. J Trauma. 2003;54(3):464-71.

10. George RL, McGwin G, Windham ST, Melton SM, Metzger J, Chaudry IH, et al. Age-related gender differential in outcome after blunt or penetrating trauma. Shock. 2003;19(1):28-32.

11. George RL, McGwin G Jr, Schwacha MG, Metzger J, Cross JM, Chaudry IH, et al. The association between sex and mortality among burn patients as modified by age. J Burn Care Rehabil. 2005;26(5):416-21.

12. Gao G-Y, Jiang J-Y. Chinese head trauma data Bank: effect of gender on the outcome of patients with severe traumatic brain injury. J Neurotrauma. 2012;150127063153001. https://doi.org/10.1089/neu.2011.2134.

13. Ramage-Morin PL. Motor vehicle accident deaths. 1979 to 2004. Health Rep. 2008;19(3):45-51.

14. Eachempati SR, Hydo L, Barie PS. Gender-based differences in outcome in patients with sepsis. Arch Surg. 1999;134(12):1342-7.

15. MacKenzie EJ, Rivara FP, Jurkovich GJ, Nathens AB, Frey KP, Egleston BL, et al. A national evaluation of the effect of trauma-center care on mortality. N Engl J Med. 2006;354(4):366-78.

16. Magnotti LJ, Fischer PE, Zarzaur BL, Fabian TC, Croce MA. Impact of gender on outcomes after blunt injury: a definitive analysis of more than 36,000 trauma patients. JACS. 2008;206(5):984-91.

17. Trentzsch $\mathrm{H}$, Nienaber $U$, Behnke M, Lefering R, Piltz S. Female sex protects from organ failure and sepsis after major trauma haemorrhage. Injury. 2014; 45:20-8.

18. Samuelsson C, Sjöberg F, Karlström G, Nolin T, Walther SM. Gender differences in outcome and use of resources do exist in Swedish intensive care, but to no advantage for women of premenopausal age. Crit Care. 2015;19(1):129.

19. Zhu Z, Shang X, Qi P, Ma S. Sex-based differences in outcomes after severe injury: an analysis of blunt trauma patients in China. Scand J Trauma Resusc Emerg Med. 2017;25(1):47

20. Larsen R, Bäckström D, Fredrikson M, Steinvall I, Gedeborg R, Sjöberg F. Decreased risk adjusted 30-day mortality for hospital admitted injuries: a multi-Centre longitudinal study. Scand J Trauma Resusc Emerg Med. 2018;26(1):24

21. Spolarics ZN. The $x$-files of inflammation. Shock. 2007;27(6):597-604.

22. Gomez D, Haas B, de Mestral C, Sharma S, Hsiao M, Zagorski B, et al. Gender-associated differences in access to trauma center care: a population-based analysis. Surgery. 2012;152(2):179-85.

23. Osler T, Rutledge R, Deis J, Bedrick E. ICISS: an international classification of disease-9 based injury severity score. J Trauma. 1996; 41(3):380-6 discussion 386-8.

24. Stephenson S, Henley G, Harrison JE, Langley JD. Diagnosis based injury severity scaling: investigation of a method using Australian and New Zealand hospitalisations. Inj Prev. 2004;10(6):379-83.

25. Charlson ME, Pompei P, Ales KL, MacKenzie CR. A new method of classifying prognostic comorbidity in longitudinal studies: development and validation. J Chronic Dis. 1987:40(5):373-83.

26. Christensen $S$, Johansen MB, Christiansen CF, Jensen R, Lemeshow $S$. Comparison of Charlson comorbidity index with SAPS and APACHE scores for prediction of mortality following intensive care. CLEP. 2011;3:203-11. 
27. Fournier A, Weiderpass E. Characteristics and recent evolution of menopausal hormone therapy use in a cohort of Swedish women. Climacteric. 2009;12(5):410-8.

28. Bergström MF, Byberg L, Melhus H, Michaëlsson K, Gedeborg R. Extent and consequences of misclassified injury diagnoses in a national hospital discharge registry. Inj Prev. 2011;17(2):108-13.

29. Gedeborg R, Warner M, Chen L-H, Gulliver P, Cryer C, Robitaille Y, et al. Internationally comparable diagnosis-specific survival probabilities for calculation of the ICD-10-based injury severity score. J Trauma Acute Care Surg. 2014;76(2):358-65.

30. Gedeborg R, Chen L-H, Thiblin I, Byberg L, Melhus H, Michaëlsson K, et al. Prehospital injury deaths-strengthening the case for prevention. J Trauma Acute Care Surg. 2012;72(3):765-72.

31. Raju R, Bland KI, Chaudry IH. Estrogen: a novel therapeutic adjunct for the treatment of trauma-hemorrhage-induced immunological alterations. Mol Med. 2008;14(3-4):213-21.

Ready to submit your research? Choose BMC and benefit from:

- fast, convenient online submission

- thorough peer review by experienced researchers in your field

- rapid publication on acceptance

- support for research data, including large and complex data types

- gold Open Access which fosters wider collaboration and increased citations

- maximum visibility for your research: over $100 \mathrm{M}$ website views per year

At BMC, research is always in progress.

Learn more biomedcentral.com/submissions 